\title{
Los viajes de Mahoma y la montaña: el concepto de transposición en Karl Bühler y Rafael Sánchez Ferlosio ${ }^{1}$
}

Sandra Santana Pérez ${ }^{2}$

Recibido: 05 de septiembre de 2017 / Aceptado: 18 de octubre de 2017

Resumen. El concepto de «transposición», tomado de la obra del psicólogo alemán Karl Bühler, le servirá a Rafael Sánchez Ferlosio para analizar el importante papel que desempeña la metáfora en el desarrollo del lenguaje humano. Este artículo ofrece una lectura comparada y complementaria de los diversos sentidos que adopta el término de «transposición» en ambos autores, así como sus implicaciones filosóficas de fondo.

Palabras claves: teoría del lenguaje; filosofía del lenguaje; metáfora; psicología; lingüística.

\section{[en] The Journeys of Muhammad and the Mountain: the Concept of Displacement in Karl Bühler and Rafael Sánchez Ferlosio}

\begin{abstract}
Rafael Sánchez Ferlosio used the concept of «displacement», taken from the work of the German psychologist Karl Bühler, to analyze the important role of metaphor in the development of human language. The purpose of this article is to provide a comparative and complementary reading of the different meanings of this concept for both authors, as well as consider the philosophical implications.
\end{abstract}

Keywords: theory of language; philosophy of language; metaphor; psychology; linguistic.

Sumario: 1. Introducción; 2. «Deixis en fantasma»: la transposición entre campos lingüísticos; 3. Isotopías: la transposición entre lugares semánticos; 4. La metáfora como actitud de experimentación; 5. Las «esferas materiales» y los contextos-situación de aprendizaje; 6. Los sentidos de la transposición: del lenguaje al mundo; 7. Referencias bibliográficas.

Cómo citar: Santana Pérez, S. (2019): “Los viajes de Mahoma y la montaña: el concepto de transposición en Karl Bühler y Rafael Sánchez Ferlosio”, en Revista de Filosofía 44 (1), 95-112.

\footnotetext{
1 El presente artículo proviene de una conferencia impartida en el marco del «I Seminario sobre lecturas contemporáneas del giro lingüístico» organizado junto con los profesores José Luis López de Lizaga y David Pérez Chico entre Febrero y Mayo de 2016 en el Departamento de Filosofía de la Universidad de Zaragoza.

2 ssantana@ull.es
} 


\section{Introducción}

Dos obras del psicólogo y lingüista alemán Karl Bühler aparecieron publicadas en España en el año 1950: Teoría de la expresión y Teoría del lenguaje. Editadas ambas por la editorial Revista de Occidente, fue la segunda la que le valió a su autor una mayor repercusión y la que marcó el destino intelectual de Bühler en nuestro país: hasta 9.000 ejemplares llegaron a venderse de esta obra en sus tres ediciones de 1950, 1961 y 1967 (Marías, p. 102). La traducción de la Teoría del lenguaje -la primera que se hizo a una lengua extranjera desde su aparición en Alemania en 1934- fue labor paciente y dilatada de Julián Marías. Paciente, porque la obra acumulaba «todos los motivos de desesperación que pueda encontrar un traductor» (Marías, p. 104) y dilatada en el tiempo a causa del robo de una maleta en la que Marías trasladaba de Soria a Madrid una cuarta parte de la traducción junto con el ejemplar alemán que le servía para trabajar. Según cuenta el filósofo español, la sugerencia inicial de traducir la obra de Bühler le llegó de Ortega y Gasset en torno a 1945, durante las extensas conversaciones de los veranos que compartieron en Lisboa ${ }^{3}$. Convencido de la fecundidad e importancia del libro, y recuperada la maleta robada, la labor de traducción fue reiniciada y dio luz a esa versión que tantos lectores logró atraer en España a lo largo de dos décadas.

A pesar de la popularidad que un día llegaron a alcanzar sus teorías entre los intelectuales españoles, es llamativo que las referencias a Bühler en la filosofía de la época, así como los estudios sobre su obra no hayan sido abundantes ${ }^{4}$. Algo a lo que contribuye sin duda la dificultad de sus escritos y la también irregular recepción que han tenido sus teorías en el resto de Europa y en Estados Unidos ${ }^{5}$. Quizá por eso es más interesante aún el caso que nos ocupa: de entre las páginas dedicadas a Bühler, tal vez no las haya más entusiastas y más cargadas de reflexiones personales que las que Rafael Sánchez Ferlosio le dedicara durante las primeras décadas de su producción ensayística. En varias ocasiones se ha referido el propio Ferlosio al modo en que la lectura de la Teoría del Lenguaje contribuyó a su aislamiento durante aquellos años de juventud a los que el mismo se refiere como sus «altos estudios eclesiásticos» ${ }^{6}$. Así, es en ensayos, artículos y notas de su primera época-como Las semanas del jardín, Guapo y sus isótopos o los «Comentarios» al informe de Jean Itard sobre Victor de l'Aveyron- donde encontramos los pasajes que más deben al denominado por Ferlosio «genio lingüístico» de Bühler.

La aproximación de Ferlosio al pensador alemán es tan entusiasta como asistemática y personal, pero no deja de ofrecer una meditada reflexión sobre algunos puntos fundamentales de sus indagaciones sobre la naturaleza del lenguaje. Lo que José Luis Pardo ha llegado a denominar una «teoría de la transposición» -en un

3 Este no será el único encargo de traducción de Julián Marías en aquel tiempo, quien, desde 1940, se había convertido en un colaborador clave para las versiones alemanas publicadas en Revista de Occidente, por entonces dirigida por el hijo de Ortega, José Ortega Spottorno (López Cobo, p. 185).

4 Al caso de Julián Marías y el de Ortega, hemos de sumar, al menos, las referencias de Gustavo Bueno a este autor en: El papel de la filosofía en el conjunto del saber, donde se sirve del modelo de Bühler en su descripción de las tres dimensiones del signo lingüístico (Gustavo Bueno, p. 124). En cuanto a los estudios sobre su obra, que sepamos, sólo existe en castellano el temprano volumen de Ramón Ceñal Lorente (1941).

5 El estudio del legado y la influencia intelectual de Karl Bühler en el siglo XX es una tarea que todavía dista de haberse completado (Brock 1994).

6 «Tras escribir El Jarama -entre octubre del 54 y marzo del 55-, agarré la Teoría del lenguaje, de Karl Bühler, y me sumergí en la gramática y en la anfetamina» (Ferlosio 2004, p. 9). 
pensador tan poco dado a las teorías como Ferlosio ${ }^{7}$, , recoge, como mostraremos a continuación, el testigo del pensador alemán y cobra con él todo su sentido y profundidad. El concepto de «transposición» («Versetzung», en el original alemán), que aparece en diversas ocasiones en la obra de Bühler, es trascendido por Ferlosio y convertido en una provechosa herramienta capaz de resolver problemas concretos que aparecen al hilo de su propia obra. Al mismo tiempo, las explicaciones dadas por Ferlosio acerca de este término vienen a alumbrar también la escritura del propio Bühler que se caracteriza por la oscura dificultad de algunos pasajes. Uniendo las páginas de Ferlosio a las de Bühler trataremos, por tanto, de dibujar el fenómeno de la «transposición» tal como aparece sugerido y perfilado en estos dos autores.

\section{2. «Deixis en fantasma»: la transposición entre campos lingüísticos}

Como señalábamos, la fascinación primera de Ferlosio por la obra de Bühler se remonta a finales de los años 50. Es sin embargo en "Glosas castellanas», un ensayo escrito entre marzo y septiembre de 1999, donde Ferlosio más explícita y extensamente se refiere a la teoría del lenguaje del autor alemán, lo que nos servirá para asentar algunos de sus fundamentos. El detonante de las reflexiones de Ferlosio en esta ocasión es un artículo de Fernando Lázaro Carreter publicado en el diario $E l$ País donde el académico habría hecho lo que Ferlosio considera un uso inadecuado del verbo «haber». Nos llevaría demasiado espacio desarrollar por extenso la polémica tratada en el ensayo que el lector puede revisar volviendo al texto, pero para lo que nos interesa podemos resumir las objeciones de Ferlosio a Lázaro Carreter diciendo que a juicio de aquel éste último se ha servido del verbo «haber» como si se tratara de un simple sinónimo del verbo «estar», obviando así el peculiar carácter que posee este elemento en el marco de la lengua (Ferlosio 2015, p. 443).

Ferlosio reclama la especificidad del verbo «haber» en su forma impersonal como «verbo traspunte». Si en la terminología teatral el traspunte es la persona encargada de indicar a los actores cuándo deben comenzar su actuación, en el ámbito de la lengua este verbo permite la puesta en escena de los elementos de la representación lingüística. Este uso del «haber», tan repetido en la formulación con que se inician los tradicionales cuentos, otorga unidad al texto y le hace estar comunicado entre sus partes creando un espacio de ficción donde el lector se orienta siendo llevado de aquí para allá con la imaginación mediante las indicaciones del lenguaje: Así, «..con "Había una vez" ("C'era una volta", "C'était une fois" (sic), "Es war ein Mal", "There was upon a time") el verbo traspunte y el artículo traspunte no sólo ponen en escena a "un pobre leñador" sino que también ponen la escena misma.» (Ferlosio 2015, p. 444). No omite Ferlosio su deuda con el que llama el «gran maestro Karl Bühler» de quien toma la terminología para explicar el caso. Desde el punto de vista de la experiencia psicológica, este efecto causado por el comienzo de los cuentos es lo que denomina Bühler una «transposición», esto es, un trasladarse el sujeto de su presente físico al lugar imaginario de la ficción narrativa. «El cuento -recuerda el

\footnotetext{
Si bien el artículo de Pardo sobre el concepto de transposición en Ferlosio no examina la herencia de Bühler, debemos a sus páginas el habernos llamado la atención sobre este problema: «Lo que merecería llamarse "la teoría de la transposición" de Rafael Sánchez Ferlosio representa, a mi modo de ver, una posibilidad lúcida y fructífera de reformular las relaciones entre concepto y metáfora (...)» (Pardo, pp. 305-306).
} 
alemán- empieza ritualmente con la indicación de la transposición: había una vez» (Bühler, p. 392). A partir de aquí el historiador o el narrador habrán de referirse a la época de un modo un poco más preciso y añadir las pertinentes indicaciones de lugar para que este traslado sea completo y el oyente o lector se encuentre rodeado por el nuevo presente de la ficción o, sencillamente, del relato de los hechos acontecidos en otro lugar o tiempo distintos al propio.

Estas «transposiciones» posibilitadas por el lenguaje resultan fundamentales en la Teoría del lenguaje de Bühler ya que le permiten transitar al receptor entre una demostratio adoculos, esto es, la mostración directa de lo que está «delante de los ojos», y una «deixis en fantasma», esto es, un señalar que se da en un contexto representado simbólicamente. Bühler, haciéndose cargo de elementos de la lingüística clásica, si bien registrando sus consecuencias para el ámbito de la psicología lingüística, dedica un extenso espacio en su obra a explicar el fenómeno de la deixis. Este término, acuñado por los estoicos y procedente de la expresión griega que significa «señalar» o «indicar», designa la referencia, por medio de unidades gramaticales de la lengua, a elementos del contexto de la comunicación y son, por tanto, dependientes de este. Así, denomina Bühler «Zeigwörte» (mostrativos) ${ }^{8}$ a los demostrativos, a los pronombres personales (yo, él, ella, etc.), y a los adverbios de tiempo y lugar (aquí, allí, mañana, ayer, etc.) (Bühler, p. 98). El referente de estos elementos lingüísticos mostrativos no se vincula a un elemento fijo sino que es relativo a una determinada posición. Esta, sin embargo, no es una posición cualquiera. Aunque variable, para Bühler, esta obedece siempre a unas coordenadas primeras ineludibles: las formadas por «el yo, el aquí y el ahora». Es a partir de ellas, de este «señalar» primero, como se abre el campo mostrativo del lenguaje: «En la forma fonética de las palabras ahora, aquí, yo, en su cuño fonético, no hay nada sorprendente; sólo es peculiar que cada una de ellas reclama: mírame a mí, fenómeno acústico, y tómame como señal del momento, una; como señal del lugar, la otra; como señal del emisor (característica del emisor), la tercera» (Bühler, p. 121).

Estas coordenadas fundamentales («yo, aquí y ahora») y, a partir de ellas cualesquiera expresiones deícticas derivadas ("tú, él, etc.; allí, más allá, etc.; mañana, ayer, etc.»), cobran significado, en primera instancia, en la copresencia. Todos estos términos requieren para su comprensión que el interlocutor acepte el punto de referencia tomado por el hablante para, a partir de ahí, comprender la referencia a otros puntos temporales o espaciales. Esto es, que el oyente acepte trasladar su propio cuerpo en el presente de la enunciación a las coordenadas que le son referidas por el hablante. Acudiendo a una experiencia de comprensión común, Bühler explica este proceso mediante el ejemplo del profesor que se pone en el lugar de los alumnos para indicarles ciertas posiciones en el espacio:

Cuando un profesor de gimnasia, de frente y cara a cara con la serie de gimnastas puestos en fila, da órdenes, la voz de mando derecha e izquierda se da y se entiende convencionalmente en la orientación de los gimnastas. Este es un caso ejemplar que hay

\footnotetext{
En su traducción, Julián Marías se refiere a estas palabras con el término de «demostrativos». Esta denominación, sin embargo resulta harto confusa ya que, a pesar de su evidente relación con lo que en nuestra gramática se denominan pronombres demostrativos, el término bühleriano no se limita a estos en su definición. Para traducir el término «Zeigwörte» nos serviremos, a partir de aquí, de la locución «mostrativos» y en las citas de la edición en castellano del libro de Bühler señalaremos el término alemán entre corchetes. Considérese como justificación añadida que el término alemán para nuestros demostrativos es «Demostrativpronomen».
} 
que tener en cuenta para explicarse la extrañamente fácil traducibilidad de todos los valores de campo del sistema de orientación y del sistema indicativo verbal de una tabla de orientación a otra (Bühler, p. 149).

Desde esta experiencia sólo hay que forzar un poco más el ejemplo para entender lo que sucede en la lectura de una narración o una novela. Allí las circunstancias cambian de golpe, «cuando un narrador lleva al oyente al reino de lo ausente recordable o al reino de la fantasía constructiva y lo obsequia con los mismos demostrativos [Zeigwörte]...» (Bühler, p. 143). Así, el escritor o narrador de cuentos se convierte en nuestro guía en esa ciudad a la que sólo podemos volver mediante la memoria (o que, tal vez, ni siquiera existe) señalando, aquí y allá, lo que en una percepción habitual el viajero que se acerca al lugar tendría ante sí. Al lector para ver y oír lo que allí se le presenta no le bastarán los oídos comunes, sino que recurrirá a esos ojos y oídos «interiores o espirituales». Es allí guiado a través de un «presente en fantasma» (Ferlosio 2015, p. 447). El lenguaje sigue sirviéndose de elementos «mostrativos» pero el oyente tiene aquí que interpretar lo ausente como una mímesis de lo presente $\mathrm{o}$, como sucede por ejemplo ante una representación teatral, interpretar «lo presente en la escena como una mímesis de lo ausente» (Bühler, p. 144).

En la literatura, y de modo fundamental en el cuento y en el teatro, se producen frecuentemente, por tanto, estas transposiciones. Es lo que tanto Bühler, como Ferlosio siguiendo a este, evocan con los viajes de Mahoma y la montaña a partir de la conocida expresión de Francis Bacon. Así, afirma el filósofo español en las «Glosas castellanas»:

(...) en el procedimiento épico, el del cuento, el sujeto hablante / oyente, Mahoma, se lleva, por transposición, el campo mostrativo de la voz-desde la voz-al campo simbólico de las representaciones del fantasma, a la montaña; en el procedimiento dramático, el de los juegos de ficción, el sujeto hablante / oyente, Mahoma, se trae al campo mostrativo de la voz el campo simbólico de las representaciones del fantasma, la montaña (Ferlosio 2015, p. 450).

Cuando, por ejemplo, inmersos en la decoración de nuestro apartamento, intentamos imaginar «aquí o allá un mueble familiar en el espacio perceptivo vacío» apreciando su efecto en el conjunto de una determinada estancia; o cuando el cuarto de juegos de los niños se convierte en la consulta del doctor o en una nave espacial («y aquí iba la camilla» y «aquí había una puerta» o «este era el asiento del capitán»), podríamos decir que «la montaña va a Mahoma». Pero si, por el contrario, al escuchar un relato o un cuento el oyente se precipita a un nuevo espacio, como los abiertos por la lectura de las Mil y una noches o como la ciudad de Combray descrita en la obra de Proust, podemos decir que es «Mahoma el que va a la montaña» (Bühler, pp. 151-155). Se explica así cómo el verbo «haber» en impersonal (y con más claridad aún si va en pasado y acompañado de «una vez», marcando el carácter de excepcionalidad y de distancia respecto del mundo circundante) nos prepara para la transposición, esto es, para ponernos en el lugar de la fantasía, donde, sin embargo, nunca prescindiremos de nuestras coordenadas corporales y temporales primeras. 


\section{Isotopías: la transposición entre lugares semánticos}

Hemos tratado ya de exponer más arriba aquello a lo que Bühler se refiere principalmente con el término «transposición», esto es, a ese cambio de posición entre el sujeto (Mahoma) y el campo mostrativo donde los objetos de mundo circundante se dan «en fantasma» (la montaña). Este término, sin embargo, hasta cierto modo marginal en la Teoría del lenguaje de Bühler, cobra protagonismo en la obra temprana de Ferlosio al aparecer como título de uno de sus ensayos lingüísticos más célebres: «Sobre la transposición». Publicado por segunda vez en 1972 en la Revista de Occidente, el texto al que nos referimos no era en origen un texto exento, sino que formaba parte de un conjunto de notas con las que el autor acompañó la obra de Lucien Malson Les enfants sauvages: Mythe et réalité $e^{9}$, más concretamente, a las memorias escritas en los albores del siglo XIX por el médico Jean Itard sobre los procesos de aprendizaje del niño Victor de l'Aveyron que se editaron junto con la obra del antropólogo francés.

Antes de abordar el sentido que el término «transposición» recibe en este texto, detengámonos un momento en el pasaje del informe de Itard que provoca el extenso comentario de Ferlosio sobre el fenómeno. Para ello es necesario trasladarse («en fantasma», como pide la teoría de la transposición) hasta la Francia napoleónica y, concretamente, hasta la casa de campo donde el médico Jean Itard pretendía enseñar a Víctor, aquel niño presuntamente criado en la soledad de los bosques, el uso del lenguaje posibilitando así el desarrollo de sus capacidades intelectuales. En el pasaje comentado por Ferlosio, según el testimonio del médico, el niño Victor, entregado al difícil aprendizaje de relacionar palabras y objetos, era tan sólo capaz al principio de reconocer bajo un mismo término objetos iguales en forma, color y tamaño. Así, cuando Itard pronunciaba la palabra «libro» asociándola a un determinado volumen, el niño atendía únicamente a buscar un objeto idéntico sin entender aún que una misma palabra puede englobar la mención de multitud de objetos diversos siempre que estos guarden un determinado vínculo semántico. En una fase posterior de su aprendizaje, sin embargo, pasa a relatar su maestro Itard cómo Víctor extiende por exceso el rango de aplicación de los conceptos asociando objetos demasiado diversos. Así, «con el nombre de "libro", por ejemplo, mentaba indistintamente una resma de papel, un cuaderno, un periódico, un libro de registros, un opúsculo...» (Ferlosio 2015, p. 568). De modo parecido responde el niño ante la solicitud de Itard quien por escrito le había pedido un cuchillo cuando, tras haberlo buscado infructuosamente durante cierto tiempo, decide traerle una navaja barbera. Victor había aprendido a «dar un mismo nombre a objetos que no guardaban entre sí más relación que la semejanza de su forma o la de su empleo» (Ibíd.). Sin embargo, Itard se ve obligado a frenar este «abuso de las semejanzas» porque, de otro modo, piensa el pedagogo, Víctor nunca adquirirá un vocabulario suficientemente amplio y se limitará a utilizar unos pocos signos.

\footnotetext{
La edición donde aparece por primera vez el texto titulado después como «Sobre la transposición» es: Lucien Malson, Los niños selváticos; Jean Itard, Memoria e Informe sobre Víctor de l'Aveyron; Rafael Sánchez Ferlosio, Comentarios, Madrid, Alianza editorial, 1973. La historia es conocida: Ferlosio se encargó de traducir y anotar para la editorial Alianza el ensayo Los niños salvajes. Mito y realidad de Lucien Malson. Las notas ocupaban tanto como el ensayo de Malson y de Itard juntos. Este hecho, junto al de que Ferlosio era crítico con la postura de Malson en algunos aspectos, hicieron que el libro se retirase de la circulación, volviendo luego a publicarse desvinculados los comentarios y la obra de Itard del libro de Malson (Ferlosio 2015, pp. 738-742).
} 
Es aquí donde Ferlosio manifiesta en forma de comentario sus dudas respecto a las conclusiones del ilustrado francés. Esta generosa disposición en la aplicación de los nombres descrita por Itard tal vez no sea un fracaso en el curso de su aprendizaje, sino la prueba misma de su éxito. Así, Ferlosio compara la actitud del niño bravío de la Francia ilustrada con los comentarios de su hija, una contemporánea niña de cinco años, que utiliza, por ejemplo, la palabra «afluente» para referirse a una calle estrecha que parte de otra vía mucho más amplia y transitada; o que se sirve del concepto «tubería» para definir el conducto que deja el gusano al atravesar la carne de una manzana ${ }^{10}$. Tanto la niña de hoy criada en un entorno normalizado como el niño supuestamente crecido en los bosques de l'Aveyron, utilizan un nombre aparentemente erróneo para denominar lo que se les presenta ante los ojos, pero lo hacen en base a cierto parecido en forma o función que estas cosas manifiestan con un objeto previamente conocido. Ferlosio llama la atención sobre el hecho de que el resultado de las audacias verbales de estos niños podría parecerse a lo que comúnmente se denomina en retórica adulta una metáfora y recurre de nuevo aquí para probarlo a la autoridad del lingüista alemán:

La metáfora del adulto, la metáfora propiamente dicha, implica -según la fórmula de Karl Bühler- una superposición de «esferas materiales» o «campos semánticos» y, por lo tanto, la conciencia de que se pone en juego un elemento léxico perteneciente a una esfera intrusa, una palabra ajena al acervo propio del concepto en cuestión (Ferlosio 2015, p. 697).

En esta definición del fenómeno de la metáfora tomada de Bühler, se afirma la existencia de una superposición de «esferas materiales o campos semánticos», lo que parece establecer una relación entre ámbitos de experiencia y campos conceptuales. Efectivamente, Victor pone en juego un elemento de la esfera de los utensilios de afeitado (navaja de barbero) para referirse a un elemento del ámbito de los cubiertos de mesa (cuchillo). La niña toma un nombre exclusivo del campo semántico de los accidentes hidrográficos (afluente) y se sirve de él para describir un elemento perteneciente al trazado urbanístico de las calles (bocacalle). Sin embargo, asumiendo que tanto el concepto de navaja como el concepto de afluente hayan salido de un contexto o esfera propios, ¿qué clase de vínculo hace a los objetos reunirse en esferas o a las palabras quedar integradas en campos de unidad semántica?

La cuestión acerca del vínculo que se establece entre términos de un mismo campo semántico no era nueva para Ferlosio. Éste había reflexionado ya en «Guapo» y sus isótopos ${ }^{11}$, tres años antes de la primera publicación del libro de Malson, acerca de cómo entre las palabras se establecen ciertas relaciones que no son ni enteramente conceptuales ni enteramente gramaticales, sino que obedecen a «la opaca propensión de las palabras mismas a organizarse con arreglo a vínculos de hecho» (Ferlosio 2015, p. 321). Así, reflexionaba Ferlosio en este texto sobre cómo el vínculo que se crea entre determinados términos (por ejemplo entre «guapo, mono y lindo») hace estridente su uso conjunto en un mismo predicado (así, por ejemplo, «ese niño es

10 Concretamente los ejemplos referidos por Ferlosio son: «no sabía que esta calle era afluente de la calle tal» y «Si tuviera gusano tendría que verse alguna tubería» (Ferlosio 2015, pp. 696-697).

11 El texto de este ensayo permanecerá inédito hasta 2009, fecha en que se publicará con anotaciones y revisiones del propio autor en la editorial Destino. 
guapo y lindo»). Esta estridencia según el autor no puede resolverse aludiendo a una incompatibilidad lógica (ya que no son términos contrarios, ni tampoco estrictamente redundantes) o meramente gramatical (pues la secuencia de adjetivos no contradice ninguna regla de este ámbito). La incompatibilidad de estos términos la atribuye Ferlosio a un fenómeno léxico que denomina «isotopía» y que viene a manifestar la pertenencia de los adjetivos antes mencionados a un mismo «lugar» lingüístico:

La isotopía sería el presunto vínculo que se crea entre dos o más palabras por el hecho de ser tenidas por respuestas a una misma cuestión, como lo son el rojo y el verde del semáforo, que no pueden estar encendidos a la vez, ya para los peatones, ya para los coches; «son isótopos» quiere decir «son implementos» del mismo lugar semántico y son, por consiguiente, incompatibles en la misma predicación o atribución (Ferlosio 2015, p. 319).

Aunque Ferlosio no lo señala expresamente, puede no ser del todo arriesgado suponer que estos «lugares» tengan que ver con los «campos» que, según la definición bühleriana aceptada por el autor, se superponen para dar lugar a una metáfora o para servirse de un término en «sentido figurado»" ${ }^{12}$. Si la metáfora consistía en superponer campos semánticos o esferas materiales, esto es, en sacar un término de su ámbito de uso habitual y llevarlo hacia un nuevo lugar en el marco de la lengua, aquí nos encontramos con una pista que nos llevará a reconocer esos lugares de y hacia donde los términos son traídos y llevados.

Dejemos de lado de momento el problema de los usos lingüísticos de la niña ferlosiana y el niño de Itard y pongamos nuestra atención en la tradicional metáfora para observar lo que ocurre allí con estos lugares semánticos. Si observamos el manido ejemplo metafórico de los labios y los rubíes («sus labios son rubíes»), del que el propio Ferlosio se sirve en «Sobre la transposición», podríamos pensar que la palabra rubí pasa de su campo semántico propio (el formado por las piedras preciosas) a otro campo en el que se comporta de manera figurada (el campo semántico de los elementos del rostro). Resulta evidente que al entrar a significar en el ámbito de la fisionomía del rostro, el rubí pierde algunas de sus características principales (por ejemplo, la de ser un mineral) pero conserva otros atributos como su valor o su belleza. El adulto que sabe manejarse con metáforas cuenta con la flexibilidad de los términos para ser trasladados de un campo semántico a otro, pero sabe también que esto no se puede hacer de cualquier modo, pues existen atributos que un concepto no abandona nunca. En el caso del rubí es su «rojez» precisamente lo que se traslada en primer lugar del escaparate de la joyería al rostro amado, y es esta la nota que, en definitiva, nunca abandonará al concepto al ser llevado a cualquier otro contexto lingüístico. Así, esta rojez que lo caracteriza por antonomasia hace imposible formular una metáfora como «sus ojos de rubí» sin caer en el más estrepitoso fracaso lírico.

12 Como conjuntos de palabras de la misma categoría gramatical que comparten un elemento o idea de significado común -ejemplos recurrentes son el campo semántico de las flores (amapola, geranio, azucena, clavel, lirio, etc.) y también el de las piedras preciosas- «mono, lindo y guapo» podrían considerarse un campo semántico formado por adjetivos con un núcleo común apreciativo de los rasgos fisionómicos. En todo caso, la isotopía llama la atención sobre la naturaleza de un vínculo, el de ser respuesta a una misma cuestión, que viene a «cuajar», según Ferlosio, en la «concreta eventualidad de los decires», pero que «cristaliza» en el «propio fuero de la lengua en forma de relaciones permanentes entre las palabras» (Ferlosio 2015, p. 330). 
El porqué de estas restricciones a la hora de trazar semejanzas puede esclarecerse si hacemos recaer nuestra atención en el rubí, y lo devolvemos al lugar semántico que le es propio, esto es, al conjunto o campo semántico de las piedras preciosas. Allí encontraremos el término dentro de la serie: «diamante», «esmeralda», «zafiro», «turquesa», etc. Considérese que todas estas piedras tienen en común su valor, su belleza, su brillo, su rareza, etc., pero que se diferencian fundamentalmente en un rasgo, esto es, en el color. El rojo representa, por tanto, dentro de la serie «el predicado diferencial de esta piedra entre las demás piedras preciosas» (Ferlosio 2015, p. 702). Esto es lo que va a denominar Ferlosio un «núcleo diferencial o especificador», una nota que diferencia a los términos de una determinada serie o campo semántico ${ }^{13}$. Por supuesto, resulta evidente que no es siempre el color la nota que distingue semánticamente a los términos dentro de un determinado campo. Si nos desplazamos, por ejemplo, del ámbito de las «piedras preciosas», al de las «partes del cuerpo», veremos cómo, según apunta Ferlosio, la nota distintiva no es allí el color sino la función: así la «mano» y el «pie» humanos son términos opuestos en tanto que sirven para coger y andar respectivamente:

El coger y el andar definen, respectivamente, la mano y el pie del hombre -objeto y modelo indudable de la fijación de ambos conceptos-y el concepto de «coger» sería para el de «mano» lo que el de «rojo» es para el de «rubí» y el de «verde» para esmeralda, o sea el momento íntimo e inalienable del concepto (Ferlosio 2015, p. 707).

Así, es también la función la que determina y define, por ejemplo, las herramientas del carpintero o el herrero (la lima y la escofina se distinguen por su función respectivamente en cada uno de los talleres en los que es habitual su uso) pero también en la cocina de la casa, un espacio más cotidiano para nosotros, podemos poner a prueba el evidente dominio de la utilidad en los numerosos nombres creados mediante la substantivación de un verbo con los que nos referimos a los utensilios de cocina: "colador", "pelador", "picadora", "tostadora" o "tenedor", parecen conservar en el nombre la nota semántica que los define por su función ${ }^{14}$. Atendiendo, por tanto a la función distintiva, no tendría nada de raro ni de estridente (siguiendo un ejemplo tomado de Ferlosio) que quien, conociendo el entorno de la herrería, al visitar por primera vez una carpintería y viendo allí al artesano manejando la escofina inmediatamente pronuncie la palabra «lima»o «lima de hierro». Así como, se me ocurre, que no parecería extraño que un niño llevado por primera vez a un puerto marítimo se sirviera de la expresión «colador para peces» para referirse a las redes de los pescadores ${ }^{15}$.

13 Si bien no es claro que se correspondan en todos los casos (por ejemplo, como se discutirá más adelante, en la identificación de la mano con el acto de «coger»), nótese la frecuente coincidencia entre el «núcleo diferencial» ferlosiano y el de «sema diferenciador» establecido por la lingüística clásica dentro de un campo semántico dado.

14 Señala Ferlosio el curioso modo en que los instrumentos u objetos funcionales tienden a tomar directamente su nombre del verbo que designa la función (como «raspador»), si bien «no faltan ejemplos de nombres descriptivos, como plomada» (Ferlosio 2015, p. 713). Del mismo modo, aunque no todas las piedras preciosas conserven la nota distintiva del color en la etimología de su nombre, nótese cómo sí lo hace la palabra rubí (procedente del latín ruber-rojo-).

15 Por contraste una cierta repulsa lingüística asoma, sin embargo, según el autor, al escuchar llamar «manos»a las patas delanteras de un caballo, como en ocasiones ha podido él mismo escuchar en el entorno rural (Ferlosio 2015, p. 705). El problema aquí es claro: en la descripción no se atiende a la verdadera nota definitoria de 
En el caso de «guapo», «lindo» y «mono» la distinción evidentemente no reside en la función pero, siguiendo los argumentos de Ferlosio, podríamos ya vislumbrar a qué se debe la estridencia que nos produce la expresión «qué guapo y lindo es este niño», una vez descartada la estricta incompatibilidad lógica o gramatical. La incompatibilidad lingüística que señala Ferlosio en su ensayo apuntaría al hecho de que los conceptos se inscriben por costumbre en series o conjuntos diferenciados por notas especificadoras que los distinguen entre $\mathrm{si}^{16}$. Adjetivos como «guapo», «lindo» y «mono» no significan exactamente lo mismo, pero sus diferencias de matiz nacen al estar inscritos en una determinada serie y precisamente del contraste entre ellos como términos isótopos ${ }^{17}$.

\section{La metáfora como actitud de experimentación}

Ya hemos visto cómo los niños parecen ser un grupo de estudio privilegiado para considerar la superposición de campos semánticos, fenómeno tan cercano a la creación de metáforas. Así, vienen a sumarse al pequeño Victor de l'Aveyron educado por Itard, y a la niña observada por Ferlosio, los numerosos niños de los experimentos psicológicos realizados por Bühler y su esposa, la psicóloga de la infancia Charlotte Bühler, así como los protagonistas de las frecuentes observaciones de la vida cotidiana infantil tomadas por el lingüista. Efectivamente también en la Teoría del lenguaje se refiere Bühler expresamente a las metáforas infantiles para justificar cómo es este un procedimiento natural de la lengua que surge, según el autor, «siempre que un fenómeno sugestivo provoca una necesidad expresiva por falta de palabras»:

(...) quiero citar como testigos de la diversidad dos metáforas enunciadas por niños: «La sopa está constipada» y «la mariposa hace calceta». Allí había aparecido una burbuja en la superficie de la sopa en el plato, y aquí, una mariposa parada entrecruzaba de un modo cambiante sus largas antenas a derecha e izquierda, exactamente como hace la abuela con largas agujas de hacer media. En tales casos nos resulta claro que la composición que mezcla esferas distintas es la técnica de abstracción psicofísicamente más sencilla (...). El creador lingüístico no hace en este caso nada más (pero ciertamente tampoco nada menos) que ver lo característico y servirse de la ley fundamental de la llamada abstracción por semejanza. Así nacen en la vida infantil las innumerables denominaciones curiosas que nadie registra (Bühler, p. 364).

\footnotetext{
la mano que es el «coger». Encuentra el autor, sin embargo, perfectamente aceptable hablar de «juego de muñecas» en el caso de las jacas de rejoneo que hacen ostentación de habilidades poco frecuentes en los caballos. Respecto a este caso, dice Ferlosio que no nos encontraríamos aquí propiamente con una metáfora: dado que los animales «simulan» ser danzantes, el término muñeca se atiene en este caso en «sentido propio» a lo representado (Ibídem, p. 710).

16 El uso lingüístico que, aventura Ferlosio, da lugar a la serie residiría en su posible carácter primero de alabanza y en la «marcada tendencia» de esta a «prodigarse en serie ya en el propio decir». Así el uso de «jbonito!, ¡guapo!, ¡precioso!» vendrían a ser términos isotópicos por una primera y frecuenten aparición en el habla común (Ferlosio 2015, pp. 365s).

17 Acerca del problema de la isotopía en particular y, en general, un lucidísimo ensayo sobre las cuestiones lingüísticas ferlosianas puede encontrarse en el texto de Carlos Piera citado en la bibliografía. Aprovecho asimismo para agradecer al profesor Piera su generoso asesoramiento en la revisión de este artículo.
} 
Para Bühler la importancia de este recurso en el que dos términos «superponen» sus esferas o campos semánticos no se reduce al ámbito de lo literario o retórico, ni a la actitud lúdica de la edad infantil, sino que encuentra su medio en el lenguaje cotidiano: «Al que empieza a prestar atención al fenómeno lingüístico que se suele llamar metáfora - dice Bühler-, le parece el habla humana tan compuesta de metáforas como la selva negra de árboles» (Bühler, p. 361). Para mostrar cómo el lenguaje de uso común está trufado de metáforas, aunque esta impresión se sustraiga a primera vista, Bühler se refiere a algunos términos alemanes como «Fingerhut» (lit. sombrero del dedo = dedal) o «Handschuh» (lit. zapato de la mano = guante). En realidad, estos términos no son utilizados a día de hoy como metáforas (aunque lo fueran en su origen etimológico), ni siquiera se utiliza en sentido figurado. Se trata de sustantivos comunes que se reconocen como compuestos por la unión de dos términos procedentes de lugares semánticos diversos.

Lo mismo sucedería en lengua castellana, no tan dispuesta como el alemán a la formación de sustantivos compuestos, con las expresiones «pie de lámpara»o «brazo del sofá»», donde los términos «pie» y «brazo» se han tomado prestados de un contexto semántico ajeno a ese otro en el que ahora se aplican con total naturalidad. En todos estos casos, el parecido con el procedimiento metafórico habitual, esa «superposición de esferas» de la que hablábamos antes, es notable. Esto sugiere cómo en el origen etimológico de muchos conceptos podría acontecer ese buscar del niño (o del adulto) entre los términos conocidos aquél que se adapte por analogía al nuevo objeto que llama la atención de sus sentidos o que requiere ser nombrado o, dicho de otro modo, esa «ley de abstracción por semejanza» de la que hablaba Bühler. La superposición de esferas parece, por tanto, no ser más que un procedimiento de economía lingüística, si bien altamente sofisticado. Los adjetivos «precioso» (referido a la belleza de un objeto, y no a su precio) o «brillante» (referido a la inteligencia de un individuo y no a un objeto que sobresale entre las cosas mate) se suman a los ejemplos que permiten señalar cómo el procedimiento metafórico (entendido en un sentido amplio como superposición de lugares semánticos) no es algo que se circunscriba estrictamente al ámbito poético (Ferlosio 2015, pp. 330-331).

Parece, por tanto, que «la actitud de experimentación del niño» manifiesta en Victor, en la niña de Ferlosio y en los ocurrentes niños estudiados por Bühler; esa en virtud de la cual se van haciendo «paso a paso y a medida que tiene éxito» con el manejo del mundo entorno, está también en la base misma de la creación lingüística del hombre adulto. Así:

El niño cambia despreocupadamente de una actitud a otra, y, por ejemplo, el trozo de madera que hace un momento «era» un hijo adoptivo que lloraba y al que mimaba, en el instante siguiente lo echa tranquilamente a la estufa. Y nunca es el hijo adoptivo sino nada más que el vulgar leño es (sic) lo que arde entonces alegremente ante sus ojos (Bühler, p. 237).

Como el tronco, que puede ser para el niño un leño o un bebé que llora, para Bühler las palabras pueden ser aplicadas por los adultos en distintos contextos semánticos tratando de probar su posible éxito. Esta actitud de experimentación, que se manifiesta de forma lúdica en el cuarto de juegos, parece ser connatural al ser humano que para vivir, desde sus orígenes, ha tenido que «aprender a recolectar, cazar, etc., con suficiente éxito, y para ello dejarse llevar, exactamente igual que 
el niño, de un grado de ejercicio a otro» (Bühler, p. 237). El que algo semejante ocurre cooperativamente mediante la invención y uso de nombres, le parece a Bühler no sólo de sentido común, sino algo probado por antropólogos y psicólogos de la infancia $^{18}$.

Volviendo a los niños que formulan supuestas metáforas con tuberías o afluentes, la sensata conclusión de Ferlosio es que estos no parecen estar haciendo verdaderas metáforas porque para que así fuera deberían conocer el ámbito de aplicación original de los conceptos que está utilizando. Cuando una niña dice que una calle es un afluente o que un agujero de gusano es una tubería, no sabe aún que la palabra afluente sólo se utiliza en el contexto de la hidrografía o que las tuberías son algo con lo que se manejan los fontaneros y no los gusanos. No sabe, por tanto, que ha sacado los términos de un campo léxico para llevarlos a otro, sino que se sirve de la lengua tal y como esta se le ofrece en su natural flexibilidad y apertura. Pero lo relevante de estos ejemplos infantiles es que evidencian cómo el procedimiento de formación de conceptos parece contradecir la existencia de un proceso de generalización por abstracción (de lo particular a lo general) en la infancia, que se produciría a base de escuchar una misma palabra en contextos siempre nuevos. Más bien al contrario, habría que reconocer en ellos el carácter de generalidad como una condición nativa del concepto desde el primer instante de su alumbramiento (Ferlosio 2015, p. 699).

Los conceptos no están restringidos desde el comienzo a un ámbito específico de aplicación, sino que sólo mediante el uso van perdiendo su originaria apertura y se van especializando. El concepto, señala Ferlosio, no recibiría del contextosituación de aprendizaje más que las notas mínimas que precisa en su seno. Así, conociendo unos pocos rasgos distintivos del perro (tal vez su peculiar ladrido, o el papel de acompañantes que suelen representar en el hogar) podemos suponer que aprendimos a llamar «perro» a toda la variadísima pluralidad de individuos con los que nos toparíamos en distintas situaciones a lo largo de la vida. La superposición de esferas que tanto llama la atención en la metáfora, parece ser ahora un procedimiento habitual tanto en la educación lingüística como en la propia formación de términos que derivan de una aplicación «figurada» del sentido hasta convertirse en términos con un sentido propio. Es por ello, dice Ferlosio, que la metáfora de los adultos, aquella deliberada de la que se sirven habitualmente los poetas, sería una especie de «luz retrospectiva» sobre la situación primaria de concepto y sobre la naturaleza de la capacidad cognoscitiva del hombre. Es decir, que la superposición de campos semánticos o la traslación de un término de un campo léxico a otro sería el fundamento mismo de nuestro modo de proceder con el lenguaje y de manejarnos en el mundo.

\section{Las «esferas materiales» y los contextos-situación de aprendizaje}

En un esclarecedor ensayo ya mencionado sobre la transposición ferlosiana, afirma José Luis Pardo que el concepto originariamente no tendría casa alguna, y que la nota semántica que se lleva al mudarse de domicilio cada vez sería una «nota

18 Este modo de servirse el ser humano de conceptos y materiales de procedencia diversa recuerda al concepto de bricolage estudiado por Claude Levi-Strauss en El pensamiento salvaje. Giorgo Agamben lo describe del siguiente modo: «Al igual que el bricolaje, el juguete también se sirve de "residuos" y de "fragmentos" pertenecientes a otros conjuntos estructurales (o bien de conjuntos estructurales modificados) y el juguete también transforma así antiguos significados en significantes y viceversa». (Agamben, p. 101). 
diferencial libre»; esto es, una determinación indeterminada o una «singularidad errática» (Pardo, p. 314) que sólo mediante el uso se puede domesticar y fijar en una determinada esfera mediante la normalidad fáctica del habla ${ }^{19}$. La niña, con su afluente, tendría en la boca, siguiendo una metáfora que Pardo toma de Ferlosio, una «ganzúa conceptual» capaz de abrir la puerta a calles, caminos, ríos o carreteras, indistintamente. Sólo mediante la práctica, tal vez a fuerza de ser advertida de sus transgresiones por los adultos, aprende a restringir el campo de aplicación del concepto y es entonces y sólo entonces, cuando puede hacer metáforas «en sentido propio»; esto es, cuando aprende a servirse de los conceptos en sentido figurado.

Merece la pena, sin embargo, detenerse en lo que podría significar, frente a los experimentos lingüísticos improvisados de los niños, saber «hacer metáforas». Recuerde el lector que, volviendo a la definición de metáfora aportada por Bühler, no encontramos allí la descripción de un «traslado» de un término de un contexto a otro, sino propiamente una «superposición» de campos semánticos diversos o combinación de «esferas materiales» o «esferas de significación». Pareciera que aquel que sabe hacer metáforas no sólo es capaz de trasladar los términos de una esfera a otra, sino que cuenta con que estos superponen sus «esferas» trayendo la evocación simultánea de ámbitos diversos. Esto es, si bien el contenido del concepto no está saturado, siendo susceptible de adaptarse según las necesidades expresivas del hablante, al ser trasladado se lleva algo consigo que, si bien no puede considerarse siempre un núcleo diferencial definido, será en muchos casos una especie de aire o de aroma tomado de su contexto de uso o aprendizaje.

Así, Bühler compara el proceso psicológico de la metáfora con la unificación binocular: el mismo objeto del mundo externo se fija en las dos retinas y sin embargo en la percepción el sujeto tiene acceso a una única «visión profunda más exacta y precisa» (Bühler, p. 365) de lo que se le presenta ante los ojos. Para que ello sea posible es necesario que todo lo realmente dispar entre las dos imágenes, aquello que no puede unificarse, no sea tenido en cuenta por el sujeto. En términos muy semejantes lo expresaba Ortega y Gasset en su «Ensayo de estética a manera de prólogo $»^{20}$ cuando señalaba que lo característico de la metáfora, para el filósofo célula elemental de toda la estética, es crear conceptos nuevos superponiendo dos

19 Resumiendo la propuesta de Pardo, la muy citada formulación de Nietzsche de que la verdad son metáforas de las que hemos olvidado que lo son (Nietzsche, pp.193-194), vendría a suponer que el concepto es la «ruina de la metáfora», en tanto que originariamente tendríamos metáforas, términos no unívocos que señalan algo con amplitud y viveza, que con el uso progresivo, con la costumbre, se habrían desgastado dejándonos en las manos únicamente conceptos, esto es, metáforas muertas. Para Pardo, sin embargo, la teoría del lenguaje de Ferlosio nos pone sobre la pista de que también, o más bien, debería formularse lo contrario, esto es: que la metáfora es en cierto sentido la «ruina del concepto». Y esto, no porque sumerja al concepto en la ambigüedad, sino porque éste pierde su originaria apertura (esa que se manifiesta en la boca de los niños), al reconocerse en el habla de los adultos la existencia de lugares «propios»e «impropios» (figurados). En las páginas que siguen, sin contradecir esta interpretación, intentaremos introducir un matiz que redunda a favor del argumento: esto es, la necesidad de pensar en lugares de normalidad asentados en el uso cotidiano de la lengua y en la experiencia perceptiva (orientacional) del mundo. Una «propiedad» lingüística que, como recuerda Pardo citando a Ferlosio, no es esencial sino «de hecho» (Pardo, p. 309).

$20 \mathrm{Su}$ «Ensayo de estética a manera de prólogo» apareció en 1914 precediendo al libro de poemas El pasajero de José Moreno Villa. Que sepamos, no se ha estudiado aún la relación entre la obra de Ortega y la de Bühler, pero desde luego existe una cierta semejanza en su modo de abordar el problema de la metáfora. No resultaría extraño (aunque no es posible afirmarlo) que hubieran llegado a conocerse. Es cuando menos llamativo que en las últimas páginas de su Teoría del lenguaje, Bühler se sirva como ejemplo de una metáfora de Gómez de la Serna, lo cual es puntualizado por Marías en nota al pie en su traducción, si bien Bühler sólo menciona en su texto haberlo encontrado traducido «de una lengua extraña» (Bühler, p. 435). 
conceptos previos conocidos, como cuando mirando a través de un cristal el ojo ve, de una sola vez, el vidrio y el paisaje que hay detrás. Así, para Ortega cuando el poeta afirma que el «ciprés es el espectro de una llama muerta»: «hemos de ver la imagen de un ciprés al través de la imagen de una llama, lo vemos como una llama, y viceversa» (Ortega, p. 676). E insiste el filósofo en que no se produce una traslación en una sola dirección:

(...) la transferencia es en la metáfora siempre mutua: el ciprés es la llama y la llama es el ciprés - lo cual sugiere que el lugar donde se pone cada una de las cosas no es el de la otra, sino un lugar sentimental, que es el mismo para ambas. La metáfora, pues, consiste en la trasposición de una cosa de su lugar real a su lugar sentimental (Ortega, p. 676, la cursiva es nuestra).

Desde una temprana posición perspectivista, para el filósofo este sería el modo en que las obras de arte pueden proporcionarnos una representación, siempre en el fondo precaria o inadecuada, de nuestras vivencias íntimas del yo. Y esto porque nos ofrecen, en definitiva, una expresión más viva de nuestra interna percepción de los fenómenos externos. Para Bühler, sin embargo, el procedimiento metafórico no es, como vimos, exclusivo del ámbito del arte, sino fundamental en los procesos lingüísticos. Recurriendo a experimentos realizados en el campo de la psicología, llama la atención sobre el hecho de que los individuos al escuchar una expresión como «el anciano bosque», no sólo reciben la idea de un bosque de edad avanzada, sino que dicen percibir con él las arrugas o una piel apagada como la de un humano en su senectud. Así, los sujetos estudiados por Stählin, señala Bühler, «indicaron que el adjetivo les recuerda ciertas propiedades, por ejemplo, las arrugas de árboles viejos o líquenes que cuelgan confusamente» (Bühler, pp. 361-362), advirtiendo de la superposición de las esferas del hombre y el árbol al recibir la expresión.

Como decíamos, para Bühler este efecto común del lenguaje es también una ley que rige en todos los procesos de conocimiento. La «ley de la adición y eliminación» se manifiesta tanto en la percepción de imágenes (al eliminar las imágenes dobles), como, en un plano más elevado, en la composición lingüística (Bühler, p. 374). Bühler, formado en la escuela de la Gestalt, admite que la mente interviene en la configuración de los elementos percibidos completando la información disponible o eliminando aquella que no resulta relevante. Es de sobra conocido el modo en que esto sucede en la percepción visual, y algo semejante parece encontrar también Bühler en el modo en que la información lingüística que recibimos no basta, en muchos casos, para explicar la comprensión de un significado completo. Bühler ofrece algunos ejemplos del modo en que para la compresión del lenguaje oral el sujeto recurre a la información que le ofrece el contexto para completar los datos lingüísticos recibidos. Así, cuando el camarero escucha «un café» de boca de un cliente no necesita más para saber que éste quiere que le sirva la bebida en una taza, o si el conductor escucha sencillamente «uno» de labios del viajero le extenderá el billete $^{21}$. Los ejemplos son, podría decirse, de Perogrullo, pero basta pensar en la

21 Nótese que estos ejemplos se parece mucho al conocido juego de Wittgenstein de las Investigaciones filosóficas, en el que los albañiles se manejan con las palabras "cubo", "pilar", "losa", "viga" y del que el pensador austriaco se sirve para mostrar la insuficiencia del modelo de explicación lingüística apuntado por San Agustín en sus Confesiones (Wittgenstein, § 2). Según la interpretación de Bühler el correcto funcionamiento de este juego lingüístico en su contexto parece no deberse tanto a que se trate de un presunto juego conocido, sino al hecho de 
extrañeza de un conductor de autobús si escucha a un viajero pedirle «un café» o en la imposibilidad de hacerle entender con la expresión «uno» al camarero que quieres un billete de autobús para ver hasta qué punto el contexto completa la expresión en estos casos. Pero, ¿qué sucede cuando en lugar de un entorno cotidiano en el que se produce un acto de habla nos encontramos ante un texto exento de cualquier referencia al mundo entorno de los hablantes? Podríamos suponer que allí, si el lector no encuentra la información completa en el lenguaje, se hallaría perdido. Sin embargo, Bühler nos advierte de cómo en la práctica lingüística textual encontramos también por todas partes elipsis, huecos, aperturas que el oyente o el lector deben completar. El lector en este caso no se encuentra privado de recursos, tan sólo ha de sacarlos de su conocimiento previo del mundo y de su experiencia práctica de la vida. Es el fenómeno que el lingüista alemán denomina una «orientación material del pensamiento verbal» (Bühler, p. 190). La función de los deícticos (señalar con el dedo) parece no ser sólo, por tanto, cosa de pronombres:

La orientación material del pensamiento verbal es un fenómeno que, junto con algunos otros hechos, permite demostrar la importante tesis de que la indicación que ejecuta el dedo al señalar no sólo caracteriza la función de los demostrativos [Zeigwörte] sino que, mucho más allá de esto, se puede encontrar también en la esfera funcional de las palabras conceptuales y pertenece a las propiedades estructurales del lenguaje humano (Bühler, p. 190).

El lenguaje señala, pues, hacia un determinado contex to material en el que podemos orientarnos aunque no estemos allí presentes. Recurriendo de nuevo a experimentos psicológicos, muestra Bühler cómo los sujetos pueden fácilmente recomponer textos que se dan incompletos o sencillamente grupos de palabras aisladas, convirtiéndolos en oraciones plenas de sentido. No es únicamente el conocimiento de las leyes gramaticales lo que guía nuestra comprensión de los textos, sino una más compleja comprensión de contextos orientacionales que provienen de la experiencia directa del mundo. Contextos y entornos prácticos, y no definiciones o conceptos abstractos, es lo que recibe el lector o el oyente con los nombres. Así: «(si) se encuentra en cualquier parte la palabra "rábano", el lector se traslada inmediatamente a la mesa de comer o a la huerta» (Bühler, p. 189). De este modo, aunque las palabras aparezcan en un lugar que no les pertenece o que no es habitual, conservan siempre «el olor de su esfera». O dicho de otro modo, el hablante se traslada imaginariamente allí donde asocia aquello que ha escuchado nombrar y, así, se refiere a:

(...) la práctica vital de los usuarios habituales de signos lingüísticos de volver a aquello que representan como símbolos toda la atención y de una actividad interna propia, creadora o recreadora, como hablantes u oyentes. Se está allí con las cosas de que se habla y se deja que la actividad interna constructiva o reconstructiva se guíe en buena parte por el objeto mismo, que ya se conoce o en la medida en que está ya situado y dispuesto por el texto (Bühler, p. 189).

que los individuos completan la información lingüística dejando de lado todas las posibles interpretaciones que el contexto imposibilita. 
Al igual que cuando decimos «rábano», nos situamos en la esfera de la cocina o de la huerta, cuando escuchamos la palabra «rubí» o «diamante», no nos referimos sólo a un determinado mineral, sino a una esfera, que es también la esfera del lujo, de la joyería, etc. Volviendo a la metáfora, decir, como hace Ferlosio recurriendo a Bühler, que en ella no sólo unimos «campos semánticos», sino «esferas materiales», vendría a significar que en el lenguaje no sólo (o no principalmente) nos las tenemos que ver con determinaciones abstractas sino más principalmente, en muchos casos, con experiencias corpóreas previas que facilitan nuestra comprensión ${ }^{22}$.

\section{Los sentidos de la transposición: del lenguaje al mundo}

Resumamos para terminar los diversos sentidos atribuidos al término «transposición» en la obra de Bühler y de los cuales se sirve Ferlosio en los textos referidos: en primer lugar la transposición se refiere a la capacidad del individuo para orientarse «en fantasma» mediante el lenguaje en contextos donde no se encuentra físicamente presente. En segundo lugar la transposición se refiere al «traslado» que se produce en los procedimientos metafóricos o, sencillamente, en el aprovechamiento de la plasticidad conceptual para crear nuevos conceptos a partir de los que ya se poseen. En último lugar, la transposición es, tal vez como derivación de los dos sentidos anteriores, el contexto experiencial que se traslada (o al que nos trasladamos) en los usos lingüísticos para facilitar habitualmente la comprensión lingüística habitual. A diferencia de los campos semánticos, el término «esfera» no es exclusivamente lingüístico, sino que se refiere al mundo entorno, transido de lenguaje, pero también de experiencia corporal. Para Bühler el lenguaje, que nos permitía pasar del campo mostrativo a un campo simbólico sustituyendo nuestras coordenadas inmediatas del «yo, aquí y ahora» por otras ajenas o figuradas, nos hace volver de nuevo a la experiencia perceptiva cotidiana mediante este fenómeno lingüístico gracias al cual los términos se cargan de sentido a partir de nuestra interacción directa con el mundo.

Así, en el uso de la palabra «caballo» no alude el hablante únicamente, según Bühler, a una serie de notas conceptuales, sino al «tesoro de mi saber», esto es, por ejemplo, a la esfera de los animales o a la de los «animales domésticos» o la de los «animales útiles» (Bühler, p. 238). Del mismo modo, el oyente al escuchar la palabra «perro» no accede a un contenido conceptual aislado o a una definición lógica sino a un contexto familiar vinculado a una experiencia muy concreta. Pensando en el origen del concepto y en su relación con el vocablo, Bühler alude al hecho de que, si bien ahora este animal es sinónimo de compañía, para los humanos del pasado el perro habría sido, de entre los animales, aquel que les servía de compañero en la caza. Era esto principalmente, y no otra cosa, lo que pudo impulsar a los hablantes a distinguir al perro del resto de los animales. Que en la esfera de los animales

22 Esto nos hace pensar en el modo en que, en expresiones de linaje metafórico cotidianas como «nos recibió con cálidas palabras» o «con una cálida sonrisa», el sujeto no encuentra juntas propiamente las cualidades de un aumento de temperatura junto a la sonrisas o las palabras aludidas, sino que en la metáfora subyacente («El calor es afecto») se da por hecho una experiencia corporal elemental que es la de sentir el calor y afecto juntos desde edad temprana por medio del abrazo de los padres que sostienen al niño de cuna para cubrir sus más básicas necesidades. Este ejemplo, aunque creemos que se adapta perfectamente a las tesis de Bühler, no está tomado de este autor sino de entre los muchos en esta misma línea ofrecidos por George Lakoff y Mark Johnson (1999, cap. 4). 
domésticos, el perro era aquel que acompañaba al hombre en la caza, es algo que ya no se reconoce en la deriva etimológica de la lengua alemana, pero que emparenta el sustantivo común «Hund» («perro» en lengua alemana) con el verbo «hunt» («cazar» en lengua inglesa) $)^{23}$.

Evidentemente, no siempre es claro cuál es la nota distintiva que nos permite aislar un determinado objeto dentro de una esfera. No todos tienen como el sustantivo «rubí» una nota definitoria inalienable. De hecho, parecería que ésta se va perdiendo según el concepto va mudando desde su acuñación primera y se hace muy difícil, como le pasaba a Victor, decidir qué es aquello que nos hace llamar «libro» a uno de «familia» (que tiene páginas, pero no está destinado a la lectura), así como llamamos «libro» hoy a uno electrónico a pesar de que está bien lejos del material obtenido de la «parte interior de la corteza de las plantas» que le hizo a los romanos acuñar el término de «liber» (Corominas, vol. III, p. 643). El discípulo de Itard llamaba «libro» con razón (o al menos, habría que decir, con buenas razones) a lo que su maestro denominaba «cuaderno» o «periódico» porque en el rango de sus experiencias aún no había tenido necesidad de distinguirlos. Tanto Bühler como Ferlosio insisten en el modo en que la «razón de ser» del concepto, esto es su designio o sentido, deriva en muchos casos (si no en todos) de un contexto experiencial o de su uso concreto. Resulta revelador acerca de esto la reflexión de Ferlosio en otra de sus notas a las memorias del médico francés acerca de los distintos nombres que una misma piedra puede adoptar en distintos entornos del hogar:

La piedra de macerar carne no necesita más que ser recogida del río y puesta en la cocina, pero ya he señalado en otro lugar las vicisitudes interpretativas que, gracias a esta circunstancia de no modificación, está dispuesta a padecer por cualquier cambio de colocación: le bastaría pasar de la mesa al despacho para tomar el sentido de pisapapeles (Ferlosio 2015, p. 631).

Así se descubre cómo objetos idénticos pueden adquirir bajo nuestra mirada un valor semántico muy diferente en base a su utilidad y su aparición en un contexto: la misma piedra puede servir para macerar carne en la cocina y de pisapapeles en el despacho. Será tan sólo dentro de su esfera donde adquiera la nota diferencial que le otorga su función y de ahí su nombre ${ }^{24}$. Parecería claro, por tanto, siguiendo las teorías y ejemplos de Bühler y Ferlosio, que los conceptos sí tienen una casa, esto es, un contexto de aplicación que radica en nuestra experiencia y nuestro manejo con el mundo. Es a este contexto de aplicación al que siempre volvemos para comprender una metáfora o para completar el sentido de una oración. Parecería sin embargo también que las notas distintivas que nos permiten diferenciar conceptos no cierran su definición. Los conceptos encerrados en el nombre están siempre dispuestos para

23 Según Corominas el origen del vocablo castellano «perro» es de origen incierto, pero puede estar relacionado con la función específica del perro en el pastoreo estando fundada en la voz «prrr, brrr», con la que los pastores incitan al perro para que haga mover al ganado y para que este obedezca al perro (vol. IV, p. 498).

24 Irresistible resulta aludir a dos célebres ejemplos literarios para ilustrar el modo en que los útiles al cambiar de función se ven obligados a cambiar de nombre: recuerda, por una parte, la resistencia de Sancho en el Quijote a aceptar la denominación de «yelmo de Mambrino» para referirse a aquella bacía que su señor se puso en la cabeza, y su conocida acuñación de «baciyelmo». Pero también en Moby Dick al objeto que el carpintero del Pequod fabrica para que sirva de ataúd a Quiqueg y que acaba siendo utilizado de boya de salvamento al final de la novela. Ismael se refiere a él como «ataúd-salvavidas» («coffin life-buoy»). 
ser cambiados o traspuestos a otro lugar, y es, precisamente, esta flexibilidad que reside en el seno de la lengua aquella de la que depende nuestra capacidad para trasladarnos del mundo entorno hasta aquellos confines de la experiencia todavía inexplorados por el lenguaje.

\section{Referencias bibliográficas}

Agamben, G. (2007): «El país de los juguetes», en Infancia e Historia, Buenos Aires, Adriana Hidalgo.

Brock, A. (1994): «Whatever Happened to Karl Bühler?», en Canadian Psychology 35, 3 Julio.

Bühler, K. (1979): Teoría del lenguaje, Madrid, Alianza. (Edición alemana: Sprachtheorie. Die Darstellungsfunktion der Sprache, Frankfurt/M., Berlín, Viena, 1978)

Ceñal Lorente, R. (1941): La teoría del lenguaje de Carlos Bühler: introducción a la moderna filosofía del lenguaje, Madrid, Consejo Superior de Investigaciones Científicas, Instituto Filosófico "Luis Vives".

Corominas, J. (1981): Diccionario crítico etimológico castellano e hispánico (6 vols.), Madrid, Gredos.

Bueno, G. (1970): El papel de la filosofia en el conjunto del saber, Madrid, Editorial Ciencia Nueva.

Lakoff, G. y M. Johnson (1999): Philosophy in the Flesh, Nueva York, Basic Books.

López Cobo, A. (2016): «Revista de Occidente, el renacer de una editorial en el erial del franquismo», en José Ortega Spottorno: un editor puente entre generaciones (Mercedes Cabrera Ed.), Madrid, Alianza.

Marías, J. (1974): «Karl Bühler y la teoría del lenguaje», en Doce ensayos sobre el lenguaje, Madrid, Fundación Juan March. [Publicado también en el "Boletín Informativo de la Fundación" (1973), n. 22, p. 515-525.]

Nietzsche, F. (2009): Sobre verdad y mentira en sentido extramoral, Madrid, Gredos.

Sánchez Ferlosio, R. (2015): Ensayos I. Altos estudios eclesiásticos, Barcelona, Debate.

Sánchez Ferlosio, R. (2004): La forja de un plumifero, FNAC por cortesía de ediciones destino.

Pardo, J.L. (2010): «El concepto vivo o ¿Dónde están las llaves? Ensayo sobre la falta de contextos», en Nunca fue tan hermosa la basura. Artículos y ensayos, Barcelona, Galaxia Gutenberg.

Piera, C. (2010): «Sobre Rafael Sánchez Ferlosio y el lenguaje», Revista de libros, n 165, septiembre, pp. 26-28.

Ortega y Gasset, J. (2004): «Ensayo de estética a manera de prólogo». Obras completas. Tomo I (1202-1915), Madrid, Fundación José Ortega y Gasset, Taurus.

Wittgenstein, L. (1988): Investigaciones filosóficas, trad. de Alfonso G. Suárez y Ulises Moulines, Barcelona, Crítica. 